\title{
Cancer survival for Aboriginal and Torres Strait Islander Australians: a national study of survival rates and excess mortality
}

John R Condon ${ }^{1 *}$, Xiaohua Zhang ${ }^{1,2}$, Peter Baade ${ }^{3,1}$, Kalinda Griffiths $^{4,1}$, Joan Cunningham ${ }^{1}$, David M Roder ${ }^{5}$, Michael Coory ${ }^{6}$, Paul L Jelfs ${ }^{7}$ and Tim Threlfall ${ }^{8}$

\begin{abstract}
Background: National cancer survival statistics are available for the total Australian population but not Indigenous Australians, although their cancer mortality rates are known to be higher than those of other Australians. We aimed to validate analysis methods and report cancer survival rates for Indigenous Australians as the basis for regular national reporting.

Methods: We used national cancer registrations data to calculate all-cancer and site-specific relative survival for Indigenous Australians (compared with non-Indigenous Australians) diagnosed in 2001-2005. Because of limited availability of Indigenous life tables, we validated and used cause-specific survival (rather than relative survival) for proportional hazards regression to analyze time trends and regional variation in all-cancer survival between 1991 and 2005.

Results: Survival was lower for Indigenous than non-Indigenous Australians for all cancers combined and for many cancer sites. The excess mortality of Indigenous people with cancer was restricted to the first three years after diagnosis, and greatest in the first year. Survival was lower for rural and remote than urban residents; this disparity was much greater for Indigenous people. Survival improved between 1991 and 2005 for non-Indigenous people (mortality decreased by 28\%), but to a much lesser extent for Indigenous people (11\%) and only for those in remote areas; cancer survival did not improve for urban Indigenous residents.

Conclusions: Cancer survival is lower for Indigenous than other Australians, for all cancers combined and many individual cancer sites, although more accurate recording of Indigenous status by cancer registers is required before the extent of this disadvantage can be known with certainty. Cancer care for Indigenous Australians needs to be considerably improved; cancer diagnosis, treatment, and support services need to be redesigned specifically to be accessible and acceptable to Indigenous people.
\end{abstract}

Keywords: Cancer, Survival, Australia, Australian Aboriginal, Torres Strait Islander, Indigenous Australian, Relative survival, Cause-specific survival

\section{Introduction}

Reports from several Australian states and territories indicate that cancer mortality rates are higher for Aboriginal and Torres Strait Islander peoples (hereafter respectfully referred to as "Indigenous Australians") than other Australians for all cancers combined and for several

\footnotetext{
* Correspondence: john.condon@menzies.edu.au

${ }^{1}$ Menzies School of Health Research, Charles Darwin University, Darwin, NT, Australia

Full list of author information is available at the end of the article
}

cancer sites [1,2]. These elevations in Indigenous mortality rates are partly due to higher incidence rates for some (but not all) cancer sites [3] and partly to lower survival rates for many cancer sites [4-6]. A recent study in Queensland reported that five-year cancer survival (all sites combined) was considerably lower for Indigenous than non-Indigenous people (50.3\% compared to 61.9\%) [6].

Until recently no reliable national cancer incidence or survival statistics have been available for Indigenous Australians. As part of a project auspiced by the

\section{Biomed Central}


Australasian Association of Cancer Registries to establish national reporting of cancer statistics for Indigenous Australians, we recently reported the first assessment of completeness of Indigenous identification in national cancer registrations data and published seminational cancer incidence rates (covering $84 \%$ of the Indigenous population); this study confirmed that higher incidence rates are partly responsible for higher mortality rates for lung and other smoking-related cancers, and cervix, uterus, and liver cancers [3]. We now report national figures for cancer survival for Indigenous Australians.

Population-based cancer survival statistics are usually calculated using the relative survival method [7]. Relative survival analysis requires detailed life tables for the general population to calculate background probability of death. Relative survival analysis for Indigenous people with cancer has major limitations because life tables for the Indigenous population are only available for the single period 2005-2007 and not available by remoteness category. Previously published life tables were calculated using an inappropriate method that produced inconsistent results [8].

We therefore used relative survival analysis to calculate national cancer survival for Indigenous Australians for the period 2001-2005 using the 2005-2007 life tables and used cause-specific survival analysis to examine time trends over 15 years and compare cancer survival in urban with rural and remote areas. Relative survival analysis is the standard method to calculate population-based survival rates but is not without its limitations; causespecific survival analysis is also appropriate in the right circumstances, particularly if reliable cause of death data are available [9]. We validated cause-specific analysis by comparison with relative survival analysis in a restricted analysis using the limited Indigenous life tables that are available.

This study and the previously reported seminational cancer incidence statistics [3] provide a template for regular national reporting of cancer statistics for Indigenous Australians.

\section{Methods}

\section{Data}

Cancer registrations data for all Australians diagnosed with cancer between 1 January 1991 and 31 December 2005 was obtained from the National Cancer Statistics Clearing House for the following data items: sex; date of birth; Indigenous status; remoteness of residence category, classified in the five categories of the Accessibility/Remoteness Index of Australia (ARIA) [10]; date of diagnosis; cancer site, coded according to the International Classification of Diseases Version 10 (ICD-10) [11]; date of death; and underlying cause of death (as recorded by cancer registries). Information on stage at diagnosis was not available for most cancer sites.
The exclusion criteria were the same as used in the most recent national report of cancer survival statistics for Australia; cancers diagnosed at the time of death were excluded and people diagnosed with multiple primary cancers were included as multiple records [7]. "Cancer site" refers to either the location within the body of the primary tumor, or, for cancers that do not originate at a particular location (such as cancers of the blood and lymphatic systems) the morphological type of the cancer. Cancer site was categorized at the ICD-10 three-digit level with some sites including multiple related three-digit categories (e.g., colorectal cancer: C18, C19 and C20) consistent with those used in the national survival report. Vital status was verified by matching the national cancer registrations dataset to the National Death Index for deaths occurring up to 31 December 2007. To reduce the impact of unreliable survival curves for longer follow-up intervals due to small numbers, we truncated survival times at five years after diagnosis.

Indigenous status is not included in pathology request/ report forms (the primary source of notifications to cancer registries), so cancer registers obtain Indigenous status data from other notification sources (hospitals, radiation oncology centers, death notifications, etc). The completeness of Indigenous identification varies among the eight Australian state-based cancer registries; completeness is high for four registries since 1998 or earlier (New South Wales, Northern Territory, Queensland, and Western Australia) but less complete for the other four [3]. All registries were included in this study. All people identified as Indigenous were included in the "Indigenous" category; all others, including those with unknown or not stated Indigenous status, were included in the "non-Indigenous" category.

Data from one registry (Victoria) were excluded from cause-specific analyses because $77 \%$ of deceased cases did not have cause of death recorded; the other seven states and territories included $94 \%$ of the Indigenous Australian population in 2006 [12]. Cause of death was coded using the ICD-10 by five cancer registries. One registry coded cause of death using the International Classification of Diseases (Oncology) Version 3 (ICDO-3) topography codes; [13] these were mapped and recoded to ICD-10 codes. One registry used ICD-10 codes for most deaths but used ICD-O-3 morphology codes for deaths caused by cancers of blood and lymphatic systems. Consequently, for all seven registries, all deaths from cancers of blood and lymphatic systems were grouped together and treated as a single cause of death.

\section{All-cancer and site-specific survival}

Cancer survival (i.e., the proportion of cancer cases still alive) was estimated at one and five years after diagnosis. 
Relative survival was calculated for all cancers combined and for specific cancer sites, for cases diagnosed in 2001-2005, which were followed-up to the end of 2007. Non-Indigenous survival was adjusted to the age distribution of Indigenous cases: for all cancers combined, to the age-distribution of all Indigenous cases; for specific cancer sites, to the age-distribution of Indigenous cases for each site.

For non-Indigenous cases, background population probability of death by sex, age, and year was obtained from life tables for the total Australian population published by the Australian Bureau of Statistics (ABS) [14]. For Indigenous cases a life table for the period 2005-2007 was used because no consistent time series of life tables was available for earlier years [15]. Expected survival was estimated using the Ederer II method [16].

\section{Validation of cause-specific analysis}

Relative survival analysis could not be used for some analyses because appropriate Indigenous life tables were not available, as described above. Therefore, cause-specific survival analysis was assessed to see whether it would give comparable results to relative survival analysis. The causespecific survival rate and the relative survival rate estimate the same measure: the proportion of people that have not died from their cancer at the specified time after diagnosis. Cause-specific survival analysis uses only deaths for which the underlying cause of death is the same as the diagnosed cancer as the endpoint; relative survival analysis compares the crude survival rate with the background survival rate for the general population (adjusted to the age-sex distribution of the cohort of cancer cases).

For cause-specific analysis, a broad definition of causespecific death was applied that included death from: cancer in the same region of the body as that of the primary site; cancer of unknown primary cancer site; or unknown cause. Of deaths counted as cause-specific under this definition: $88.9 \%$ were deaths for which the diagnosis site and cause of death agreed at ICD-10 three-digit level or both the diagnosis site and cause of death were cancers of the blood and lymphatic system; $0.9 \%$ were deaths from other cancers in the same regional grouping as the diagnosis site; $8.8 \%$ were deaths from cancer of unknown primary site; and $1.4 \%$ were deaths from unknown causes.

Cause-specific was compared with relative survival analysis for the period 2001-2005, for Australia excluding Victoria, for all cancers combined, and for specific cancer sites, separately for Indigenous and non-Indigenous cases. The survival rates and regression analysis results produced by the two methods were compared for: the all-cancer survival rate by year after diagnosis (not adjusted for site or age); the five-year survival rate for specific cancer sites (not adjusted for age); and the hazard ratios from proportional hazards regression (for cause-specific survival) and Poisson regression (for relative survival [17]) models. Regression models included terms for: Indigenous status; sex; age at diagnosis; cancer site; year since diagnosis (as indicator terms); and interaction terms for Indigenous status with each of age at diagnosis and year since diagnosis. Cause-specific analysis was found to be comparable to relative survival analysis for all cancers combined, but not for some specific cancer sites (see results). Therefore time trends and regional variation in cancer survival were investigated using proportional hazard regression of cause-specific death rates for all cancers combined and for the four most prevalent cancer sites in the Indigenous population (excluding head and neck cancer, for which cause-specific and relative survival did not produce similar results).

\section{Regression analysis}

Cox proportional hazards regression was used to analyze cancer mortality of cases diagnosed in 1991-2005 for Australia, excluding Victoria. The model included terms for: Indigenous status, sex, age at diagnosis, and ARIA remoteness category (the four terms of a priori interest); cancer site; and interaction terms for Indigenous status with each of age at diagnosis (base age 59 years) and remoteness categories (base category "major cities"). These interaction terms were included because the effects of age at diagnosis and remoteness of residence (but not sex) were found to be different for Indigenous compared with non-Indigenous people. Age at diagnosis and ARIA remoteness category were each included as a single ordinal term; including them as categorical variables did not improve model fit. Cancer site was included as multiple indicator terms. Scaled Schoenfeld residuals, which test for nonzero slope over time, were used to check if the proportional hazards assumptions of each variable were satisfied. A step function of Indigenous status with followup time (as annual intervals) was also included in the model because the proportional hazards assumption was not met for Indigenous status, as has been demonstrated previously [6].

\section{Time trends}

For time trends, follow-up was limited to the first two years after diagnosis because all subjects had at least two years of potential follow-up (so that shorter follow-up time for subjects diagnosed late in the study period did not bias time trends) and because most of the excess mortality of Indigenous cases occurred in the first two years after diagnosis (see results). Time trends were analyzed for all cancers combined (adjusted for cancer site) and for four of the most prevalent cancer sites in the Indigenous population: colorectal, lung, breast (female only), and prostate. Two-year cause-specific survival for all cancers combined (adjusted for age and cancer site) 
was calculated by Indigenous status, year of diagnosis, and ARIA category. Multivariate analysis was performed using proportional hazards regression. The model included terms for: Indigenous status, sex, age at diagnosis, and year of diagnosis (the terms of a priori interest); cancer site (for analysis of all cancers combined); and interaction terms for Indigenous status with each of age at diagnosis and year of diagnosis. Variation in time trend by remoteness category was investigated by including an interaction term for ARIA category by year in separate models for Indigenous and non-Indigenous cases.

All analyses were performed using Stata (versions 11.1 and 12.1) [18]. Relative survival analysis was performed using the 'strs' procedures of Stata [17]. Ethics approvals were obtained from 12 human research ethics committees covering all states and territories, including several Indigenous committees or subcommittees. Approval to use cancer registrations data was obtained from each of the eight Australian cancer registries.

\section{Results}

1,235,592 Australians diagnosed with invasive cancer between 1991 and 2005 met the inclusion criteria for this study; $0.6 \%$ were identified as Indigenous (Aboriginal and/or Torres Strait Islander peoples) (Table 1). Indigenous cases were more likely to be female, younger, and live outside major cities. A higher proportion of Indigenous (67\%) than non-Indigenous (55\%) cases died by the end of 2007.

\section{Survival rates}

For all cancers combined (adjusted for age), survival was lower for Indigenous than other Australians (Table 2). Most of the difference arose during the first year after diagnosis; survival was $63.8 \%$ for Indigenous compared with $83.4 \%$ for non-Indigenous cases at one year after diagnosis and $46.7 \%$ compared with $70.0 \%$ at five years. Survival was lower for Indigenous than non-Indigenous cases for almost all cancer sites at both one and five years after diagnosis.

\section{Cause-specific compared with relative survival}

For all cancers combined, cause-specific survival was similar to relative survival for both Indigenous and non-Indigenous cases throughout the first five years after diagnosis, with cause-specific survival slightly higher than relative survival (Figure 1). For non-Indigenous cases cause-specific and relative survival were $80.1 \%$ (95\% CI 80.0-80.3) compared with $79.1 \%$ (78.9-79.2) at one year and $65.6 \%$ (65.4-65.8) compared with $64.6 \%$ (64.4-64.8) at five years, while for Indigenous cases $64.7 \%$ (63.0-66.4) compared with $63.2 \%(61.4-64.9)$ at one year and $47.0 \%$ (45.0-48.9) compared with $45.8 \%(43.7-47.9)$ at five years. Results of cause-specific analysis using proportional hazards
Table 1 Demographic characteristics of people diagnosed with cancer, Australia, 1991-2005

\begin{tabular}{|c|c|c|}
\hline & $\begin{array}{l}\text { Indigenous } \\
n=7,019\end{array}$ & $\begin{array}{l}\text { Non-indigenous } \\
n=1,228,573\end{array}$ \\
\hline & \multicolumn{2}{|c|}{ Percent of column total } \\
\hline \multicolumn{3}{|l|}{ Sex } \\
\hline Male & 47.8 & 55.0 \\
\hline Female & 52.2 & 45.0 \\
\hline \multicolumn{3}{|l|}{ Age at diagnosis } \\
\hline 0 to 49 years & 28.9 & 15.1 \\
\hline 50 to 59 years & 23.1 & 15.7 \\
\hline 60 to 69 years & 24.4 & 24.0 \\
\hline 70 years and over & 23.6 & 45.2 \\
\hline Median age (years) & 59 & 68 \\
\hline \multicolumn{3}{|l|}{ State of residence } \\
\hline Queensland & 30.7 & 18.8 \\
\hline New South Wales & 27.8 & 34.4 \\
\hline Western Australia & 16.2 & 8.9 \\
\hline Northern Territory & 15.5 & 0.4 \\
\hline Victoria & 4.8 & 24.7 \\
\hline South Australia & 4.1 & 8.8 \\
\hline Tasmania & 0.6 & 2.7 \\
\hline Australian Capital Territory & 0.3 & 1.3 \\
\hline \multicolumn{3}{|l|}{ Remoteness of residence } \\
\hline Major cities & 27.3 & 65.9 \\
\hline Inner regional & 15.8 & 22.5 \\
\hline Outer regional & 25.3 & 9.8 \\
\hline Remote & 11.2 & 1.1 \\
\hline Very remote & 19.8 & 0.4 \\
\hline Other ${ }^{1}$ & 0.7 & 0.4 \\
\hline \multicolumn{3}{|l|}{ Vital status at 31/12/2007 } \\
\hline Alive & 33.4 & 45.1 \\
\hline Dead & 66.6 & 54.9 \\
\hline
\end{tabular}

${ }^{1}$ Includes migratory and unknown.

regression were similar to those of relative survival analysis using Poisson regression (Table 3, Additional file 1: Table S3a); hazard ratios were similar for all terms included in the models (with the same terms in each model). For specific cancer sites, the cause-specific survival rate was similar to the relative survival rate for most sites but very different for some; differences were greater for Indigenous than non-Indigenous cases (see Additional file 2: Table S7). Cause-specific analysis was therefore restricted to analysis of all cancers combined and selected cancer sites.

\section{Regression analysis}

For all cancers combined, the cause-specific death rate was higher (i.e., cancer survival was lower) for males 
Table 2 One-year and five-year relative survival ${ }^{1}$ by Indigenous status and cancer site/type, Australia, $2001-2005$

\begin{tabular}{|c|c|c|c|c|c|c|c|c|c|c|}
\hline \multirow[b]{3}{*}{ Cancer site/type } & \multicolumn{5}{|c|}{ Indigenous } & \multicolumn{5}{|c|}{ Non-indigenous ${ }^{2}$} \\
\hline & \multirow{2}{*}{$\begin{array}{c}\text { Cases } \\
\mathbf{n}\end{array}$} & \multicolumn{2}{|c|}{ One-year } & \multicolumn{2}{|c|}{ Five-year } & \multirow{2}{*}{$\begin{array}{c}\text { Cases } \\
\mathbf{n}\end{array}$} & \multicolumn{2}{|c|}{ One-year } & \multicolumn{2}{|c|}{ Five-year } \\
\hline & & $\%$ & $(95 \% \mathrm{Cl})$ & $\%$ & $(95 \% \mathrm{Cl})$ & & $\%$ & $(95 \% \mathrm{Cl})$ & $\%$ & $(95 \% \mathrm{Cl})$ \\
\hline Head and neck (C1-14, C30-32) & 236 & 60.3 & $(53.6-66.4)$ & 32.4 & $(25.6-39.5)$ & 11893 & 86.1 & $(85.5-86.8)$ & 65.9 & $(64.9-66.9)$ \\
\hline Stomach (C16) & 73 & 39.8 & $(28.3-51.1)$ & 16.9 & $(8.0-29.0)$ & 9349 & 56.1 & $(55.1-57.1)$ & 30.7 & $(29.6-31.7)$ \\
\hline Colorectal (C18-20) & 306 & 80.1 & $(74.8-84.6)$ & 58.5 & $(50.9-65.7)$ & 62021 & 85.6 & $(85.3-85.9)$ & 66.3 & $(65.9-66.8)$ \\
\hline Anus (C21) & 22 & 73.8 & $(49.9-88.0)$ & 49.1 & $(20.9-73.8)$ & 1304 & 91.7 & $(89.9-93.1)$ & 70.4 & $(67.3-73.4)$ \\
\hline Liver (C22) & 83 & 24.8 & $(16.0-34.6)$ & 11.2 & $(5.1-20.0)$ & 4500 & 43.4 & $(41.9-44.9)$ & 19.9 & $(18.5-21.2)$ \\
\hline Pancreas (C25) & 91 & 26.3 & $(17.6-35.9)$ & 11.2 & $(5.4-19.5)$ & 9667 & 27.6 & $(26.7-28.5)$ & 7.6 & $(7.0-8.3)$ \\
\hline Lung (C33-34) & 500 & 29.4 & $(25.4-33.5)$ & 9.1 & $(6.3-12.5)$ & 42139 & 43.4 & $(42.9-43.9)$ & 16.7 & $(16.3-17.2)$ \\
\hline Melanoma (C43) & 59 & 95.6 & (84.4-100.7) & 73.8 & $(55.5-88.5)$ & 48592 & 97.9 & $(97.7-98.1)$ & 92.4 & (91.9-92.8) \\
\hline Breast (C50) & 420 & 94.1 & $(91.0-96.4)$ & 80.1 & $(74.3-85.2)$ & 59640 & 97.9 & $(97.7-98.0)$ & 89.5 & $(89.1-89.8)$ \\
\hline Cervix (C53) & 109 & 79.8 & $(70.8-86.5)$ & 57.6 & $(46.6-67.4)$ & 3475 & 90.8 & $(89.7-91.7)$ & 78.3 & (76.7-79.8) \\
\hline Uterus (C54) & 96 & 85.2 & (75.9-91.4) & 78.7 & $(66.7-88.2)$ & 7969 & 94.0 & (93.5-94.6) & 84.6 & $(83.6-85.7)$ \\
\hline Ovary (C56) & 53 & 77.1 & (62.9-86.8) & 50.1 & $(33.6-65.1)$ & 5777 & 83.5 & $(82.5-84.5)$ & 53.1 & (51.6-54.6) \\
\hline Prostate (C61) & 181 & 90.4 & $(84.0-94.9)$ & 83.6 & $(72.5-93.2)$ & 68475 & 97.3 & $(97.1-97.4)$ & 91.0 & $(90.6-91.4)$ \\
\hline Testis (C62) & 25 & 100.5 & $(100.5-100.5)$ & 94.5 & $(73.6-100.5)$ & 3209 & 98.8 & $(98.3-99.2)$ & 96.9 & (96.0-97.6) \\
\hline Kidney (C64) & 69 & 77.5 & $(65.2-86.3)$ & 68.1 & $(53.0-80.7)$ & 10522 & 84.9 & (84.2-85.6) & 73.2 & (72.1-74.2) \\
\hline Bladder (C67) & 53 & 61.5 & $(46.4-74.0)$ & 54.7 & (36.1-72.6) & 11270 & 85.2 & (84.5-85.9) & 68.1 & $(66.9-69.2)$ \\
\hline Brain (C71) & 48 & 58.9 & $(43.6-71.4)$ & 42.2 & $(26.9-56.9)$ & 6800 & 64.3 & $(63.2-65.5)$ & 40.4 & $(39.2-41.7)$ \\
\hline Thyroid (C73) & 74 & 93.0 & $(83.9-97.5)$ & 85.0 & $(69.3-94.5)$ & 6809 & 97.0 & $(96.5-97.4)$ & 96.0 & $(95.3-96.6)$ \\
\hline Hodgkin lymphoma (C81) & 26 & 96.8 & $(76.2-100.1)$ & 100.6 & $(79.2-104.0)$ & 2290 & 96.0 & $(95.1-96.8)$ & 90.3 & $(88.8-91.7)$ \\
\hline NHL (C82-85, C96) & 101 & 67.4 & $(56.9-76.1)$ & 52.0 & $(37.3-65.8)$ & 18392 & 85.5 & $(85.0-86.0)$ & 73.7 & $(72.9-74.5)$ \\
\hline Leukemia (C91-95) & 108 & 64.6 & $(54.5-73.1)$ & 53.7 & $(42.7-63.9)$ & 12864 & 80.3 & $(79.5-81.0)$ & 63.9 & $(62.9-64.9)$ \\
\hline Unknown primary (C76-80) & 196 & 29.2 & $(22.8-35.8)$ & 14.9 & $(9.9-21.1)$ & 14997 & 35.6 & $(34.9-36.4)$ & 21.3 & $(20.6-22.1)$ \\
\hline Other & 363 & 61.1 & $(55.7-66.1)$ & 40.3 & $(34.4-46.2)$ & 42463 & 78.5 & $(78.1-78.9)$ & 57.2 & $(56.7-57.8)$ \\
\hline All cancers (C00-96, D45-47) & 3292 & 63.8 & $(62.1-65.5)$ & 46.7 & $(44.6-48.7)$ & 464417 & 83.4 & $(83.3-83.5)$ & 70.0 & $(69.8-70.2)$ \\
\hline
\end{tabular}

${ }^{1}$ Relative survival rate.

${ }^{2}$ Age-adjusted to age distribution of Indigenous cases for each cancer site.

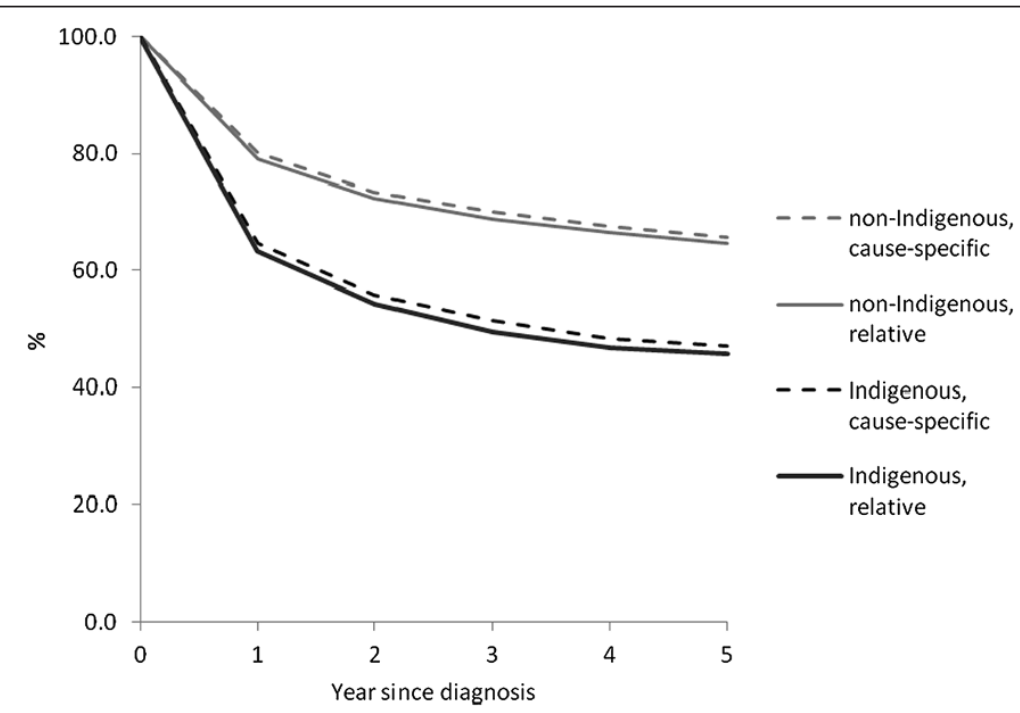

Figure 1 Cause-specific compared with relative survival, all cancers combined by Indigenous status, Australia (excluding Victoria), $2001-2005$. 
Table 3 Cause-specific compared with relative survival regression analysis ${ }^{1}$, all cancers combined, Australia (excluding Victoria), 2001-2005

\begin{tabular}{|c|c|c|c|c|}
\hline & \multicolumn{2}{|c|}{ Relative } & \multicolumn{2}{|c|}{ Cause-specific } \\
\hline & $\mathrm{HR}^{2}$ & $(95 \% \mathrm{Cl})$ & HR & $(95 \% \mathrm{Cl})$ \\
\hline \multicolumn{5}{|l|}{ Indigenous } \\
\hline 1st year after diagnosis & 1.88 & $(1.77-2.00)$ & 1.94 & $(1.82-2.06)$ \\
\hline 2nd year after diagnosis & 1.63 & $(1.43-1.85)$ & 1.64 & $(1.45-1.86)$ \\
\hline 3rd year after diagnosis & 1.66 & $(1.35-2.03)$ & 1.62 & $(1.35-1.95)$ \\
\hline 4th year after diagnosis & 1.42 & $(1.02-1.96)$ & 1.66 & $(1.28-2.15)$ \\
\hline 5th year after diagnosis & 0.65 & $(0.30-1.38)$ & 0.96 & $(0.60-1.52)$ \\
\hline \multicolumn{5}{|l|}{ Sex } \\
\hline Female & 0.92 & $(0.91-0.93)$ & 0.92 & $(0.91-0.94)$ \\
\hline \multicolumn{5}{|c|}{ Age at diagnosis (per year of age) } \\
\hline Non-indigenous & 1.03 & $(1.03-1.03)$ & 1.03 & $(1.03-1.03)$ \\
\hline Indigenous & 1.02 & $(1.01-1.02)$ & 1.02 & $(1.01-1.02)$ \\
\hline
\end{tabular}

'Both models were also adjusted for cancer site (see Additional file 1: Table S3a). ${ }^{2}$ Hazard ratio.

than females; for older than younger cases; and for remote than urban residents (Table 4, Additional file 3: Table S4a). The effects of age at diagnosis and remoteness were different for Indigenous than non-Indigenous cases. The death rate increased by $3 \%$ per year of age for non-Indigenous cases but by $2 \%$ for Indigenous cases; this was because death rates were relatively high for younger Indigenous cases. Death rates were higher for those resident in very remote compared with metropolitan areas: $23 \%$ higher for

Table 4 Regression analysis ${ }^{1}$ of cause-specific mortality for all cancers combined, Australia (excluding Victoria), 1991-2005

\begin{tabular}{|c|c|c|}
\hline & $\mathrm{HR}^{2}$ & $(95 \% \mathrm{Cl})$ \\
\hline \multicolumn{3}{|l|}{ Indigenous $^{3}$} \\
\hline 1st year after diagnosis & 1.50 & $(1.41-1.60)$ \\
\hline 2nd year after diagnosis & 1.23 & $(1.11-1.35)$ \\
\hline 3 rd year after diagnosis & 1.21 & $(1.07-1.38)$ \\
\hline 4th year after diagnosis & 1.16 & $(0.98-1.37)$ \\
\hline 5th year after diagnosis & 0.99 & $(0.79-1.23)$ \\
\hline \multicolumn{3}{|l|}{ Sex } \\
\hline Female & 0.93 & $(0.92-0.93)$ \\
\hline \multicolumn{3}{|c|}{ Age at diagnosis (per year of age) } \\
\hline Non-indigenous & 1.03 & $(1.03-1.03)$ \\
\hline Indigenous & 1.02 & $(1.02-1.02)$ \\
\hline \multicolumn{3}{|c|}{ Remoteness (per ARIA category) } \\
\hline Non-indigenous & 1.05 & $(1.05-1.06)$ \\
\hline Indigenous & 1.13 & $(1.11-1.16)$ \\
\hline
\end{tabular}

non-Indigenous but $65 \%$ higher for Indigenous cases. The effect of sex was similar in Indigenous and nonIndigenous cases; the hazard ratio for an interaction term for Indigenous status by sex was not statistically significant, so an interaction term for "Indigenous status by sex" was not included in the final model.

\section{Time trend in two-year survival rate}

Cancer survival improved considerably for non-Indigenous cases, but less so for Indigenous cases. The death rate in the first two years after diagnosis decreased by $2 \%$ per year for non-Indigenous ( $28 \%$ decrease over 15 years), but by only $1 \%$ per year for Indigenous cases (11\% over 15 years) (Table 5, Additional file 4: Table S5a).

For non-Indigenous cases this decrease over time was similar for all ARIA categories (hazard ratio [HR] for interaction term "year by ARIA category": 1.00, 95\% CI 1.00-1.00) (see Additional file 5: Table S8). For Indigenous cases survival increased for residents of remote and very remote areas but not for urban residents (Figure 2). This was confirmed by multivariate analysis (see Additional file 5: Table S8); the time trend was different for urban compared with rural and remote residents (HR for interaction term "year by ARIA category": 0.992, 95\% CI 0.986-0.998). The death rate decreased over time for Indigenous cases residing in more remote areas, by 26\% between 1991 and 2005 in the "very remote" ARIA category (HR 0.98 per year, 95\% CI 0.97-0.99), but did not decrease over time for Indigenous cases resident in the "major metropolitan" ARIA category (HR 1.01, 95\% CI 0.99-1.03).

Table 5 Time trends: regression analysis ${ }^{1}$ of cause-specific mortality in two years after diagnosis for all cancers combined, Australia (excluding Victoria), 1991-2005

\begin{tabular}{lll}
\hline & $\mathbf{H R}^{\mathbf{2}}$ & $\mathbf{( 9 5 \% ~ C l )}$ \\
\hline $\begin{array}{l}\text { Indigenous } \\
\text { Sex }\end{array}$ & 1.54 & $(1.42-1.66)$ \\
$\quad$ Female & 0.95 & $(0.94-0.95)$ \\
Age at diagnosis (per year of age) & & \\
$\quad$ Non-indigenous & 1.03 & $(1.03-1.03)$ \\
$\quad$ Indigenous & 1.02 & $(1.02-1.02)$ \\
Remoteness (per ARIA category) & & $(1.06-1.07)$ \\
$\quad$ Non-indigenous & 1.06 & $(1.13-1.19)$ \\
$\quad$ Indigenous & 1.16 & $(0.98-0.98)$ \\
Year of diagnosis (per year) & & $(0.98-1.00)$ \\
$\quad$ Non-indigenous & 0.98 & \\
$\quad$ Indigenous & 0.99 &
\end{tabular}

${ }^{1}$ The model was also adjusted for cancer site (see Additional file 4: Table S5a). ${ }^{2}$ Hazard ratio.

${ }^{3}$ Applies to the reference categories of the interaction terms (i.e., people of median age 59 years in 2005). 


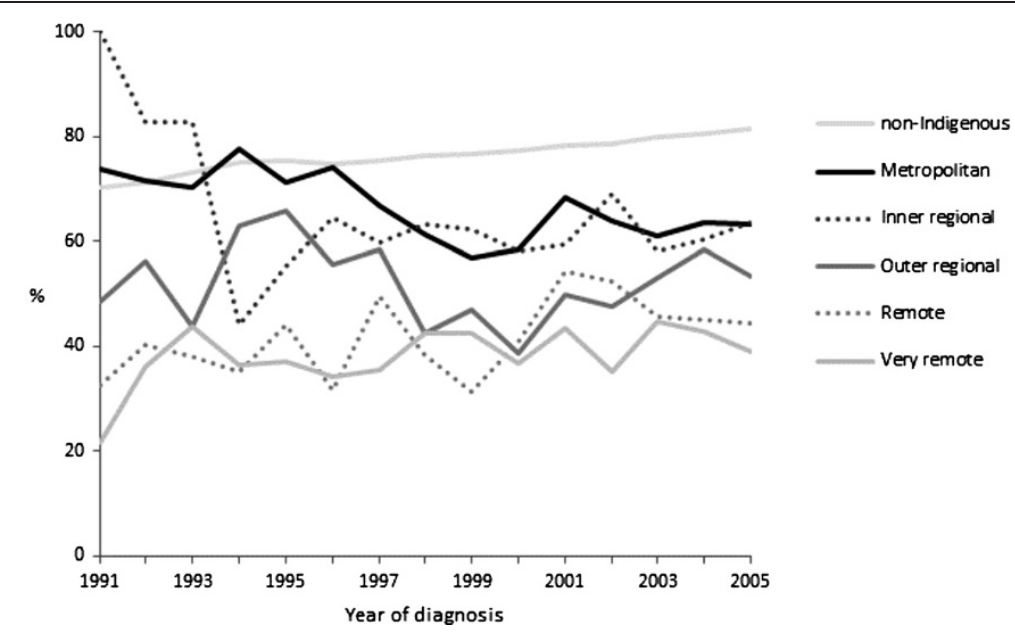

Figure 2 Two-year cause-specific survival rate by year of diagnosis, all cancers combined, indigenous by ARIA category and non-indigenous, Australia (excluding Victoria), 1991-2005.

Time trends were also examined for four of the most prevalent cancers in the Indigenous population: colorectal, lung, breast (female only), and prostate (Table 6). For non-Indigenous cases death rates decreased for all four cancers. For Indigenous people with colorectal and breast cancer, death rates decreased to a similar extent as for non-Indigenous cases, but there was no decrease for lung and prostate cancer.

\section{Discussion}

Survival is lower for Indigenous than other Australians with cancer, for all sites combined, and for many individual cancer sites. This disparity is greatest immediately after diagnosis, greater for remote than metropolitan residents, greater for younger than older people, and is increasing over time.

\section{Cause-specific survival analysis}

Although not without potential limitations, [9] relative survival is the preferred method for population-based cancer survival analysis (as distinct from clinical studies) because of concerns about accuracy of classification of cause of death, and because for many cancer cases, cancer is not the only condition contributing to their death. However, the inadequacies of life tables for the Australian Indigenous population limit the applicability of the relative survival method for analysis of time-trends and variation by remoteness of residence. The ABS has determined that the non-standard methods used to calculate Indigenous life tables before 2005 [19] were unreliable and produced considerably inaccurate results [20]. The ABS has subsequently published Indigenous life tables for 2005-2007 using the standard method used for the total

Table 6 Time trends: regression analysis of cause-specific mortality in two years after diagnosis for specific cancers, hazard ratio (95\% confidence interval), Australia (excluding Victoria), 1991-2005

\begin{tabular}{|c|c|c|c|c|c|c|c|c|}
\hline \multirow[b]{2}{*}{ Indigenous $^{1}$} & \multicolumn{2}{|c|}{ Colorectal } & \multicolumn{2}{|c|}{ Lung } & \multicolumn{2}{|c|}{ Breast } & \multicolumn{2}{|c|}{ Prostate } \\
\hline & 1.44 & $(1.05-1.97)$ & 1.42 & $(1.21-1.66)$ & 1.66 & $(1.06-2.61)$ & 5.59 & $(3.15-9.94)$ \\
\hline \multicolumn{9}{|l|}{ Sex } \\
\hline Female & 1.02 & $(1.00-1.04)$ & 0.90 & $(0.89-0.92)$ & $\mathrm{n} / \mathrm{a}$ & & $\mathrm{n} / \mathrm{a}$ & \\
\hline \multicolumn{9}{|l|}{ Age at diagnosis } \\
\hline Non-indigenous & 1.03 & $(1.02-1.03)$ & 1.02 & $(1.02-1.02)$ & 1.04 & $(1.04-1.04)$ & 1.08 & $(1.08-1.08)$ \\
\hline Indigenous & 1.00 & $(0.99-1.01)$ & 1.01 & $(1.01-1.02)$ & 1.00 & $(0.99-1.02)$ & 1.02 & $(1.00-1.05)$ \\
\hline \multicolumn{9}{|c|}{ Remoteness (per ARIA category) } \\
\hline Non-indigenous & 1.08 & $(1.06-1.09)$ & 1.07 & $(1.06-1.08)$ & 1.06 & $(1.03-1.10)$ & 1.13 & $(1.10-1.16)$ \\
\hline Indigenous & 1.19 & $(1.07-1.33)$ & 1.08 & $(1.03-1.14)$ & 1.29 & $(1.13-1.48)$ & 1.35 & $(1.12-1.64)$ \\
\hline \multicolumn{9}{|c|}{ Year of diagnosis (per year) } \\
\hline Non-indigenous & 0.97 & $(0.97-0.98)$ & 0.99 & $(0.99-0.99)$ & 0.96 & $(0.95-0.96)$ & 0.96 & $(0.95-0.96)$ \\
\hline Indigenous & 0.97 & $(0.94-1.00)$ & 1.00 & $(0.98-1.02)$ & 0.97 & $(0.92-1.02)$ & 1.06 & $(0.99-1.13)$ \\
\hline
\end{tabular}

${ }^{1}$ Applies to the reference categories of the interaction terms (i.e., people of median age 59 years in 2005). 
Australian population but has not published a retrospective time series [15] or published Indigenous life tables stratified by remoteness category (but is expected to do so in late 2013).

Life tables stratified by Indigenous status also have a potential for differential misclassification of Indigenous status between the life tables and the cancer registration data. If, for example, Indigenous status was less complete in the deaths data used to calculated probability of death in life tables than in cancer registers, the life tables would underestimate probability of death for the background Indigenous population, and consequently, relative survival analysis would underestimate cancer survival. Death and cancer registers both rely on death notifications and hospital records (for deaths occurring in hospital) for Indigenous status data, so this potential differential misclassification may not be large, but there is no evidence available to test this.

Over time, improvements in the accuracy of Indigenous mortality data may provide more detailed and consistent Indigenous life tables that will enable use of relative survival for more detailed analysis of survival for Indigenous people with cancer. In the interim, our comparison of cause-specific with relative survival analysis indicates that cause-specific analysis is as reliable as relative survival for analysis of time trends and regional variation in cancer survival for all cancers combined and some specific cancer sites.

For all cancers combined and for most cancer sites relative survival and cause-specific survival produced similar results (see Additional file 2: Table S7 and Additional file 5: Table S8), but for some specific sites such as head and neck, bladder, and leukemia the two methods produced very different results. Where there was a large difference between the two methods, cause-specific survival was mostly higher than relative survival. Underestimation of cancer-related deaths for people with these cancers would produce this effect, either because deaths due to cancer were misclassified or a high proportion of deaths were partially attributable to these cancers but few were classified as cancer deaths [9]. Alternatively, for these sites relative survival might be underestimated because the probability of noncancer related death for people with these cancers is higher than for the general population. This is plausible for head and neck cancer and bladder cancer because they are smoking-related, and the probability of noncancer death for people with these cancers would be higher than that of the general population (most of whom are not smokers). However, this is not consistent with the results for other smoking-related cancers such as lung and pancreas, for which relative and causespecific survivals were similar. It is not obvious why relative and cause-specific survivals are so different for some cancer sites.

\section{Limitations}

Identification of Indigenous people in cancer registrations data is known to be high for four of the eight registries included in this study (New South Wales, Northern Territory, Queensland, and Western Australia), which cover $84 \%$ of the Indigenous population [3]. We have included data from the other four registries with low identification of Indigenous people (Australian Capital Territory, South Australia, Tasmania, and Victoria) (Table 1). Consequently it is likely that a proportion of Indigenous people were misclassified as non-Indigenous in this study. Indigenous cases comprised $0.6 \%$ of cases, which is less than the proportion of Indigenous people in the total Australian population (0.9\% in the 50+ age-group in 2006), [12] but cancer incidence is different for many cancer sites for Indigenous than other Australians, including being lower for several of the most common cancers (breast, colon and rectum, prostate, and melanoma) [3] so a direct comparison of population proportions is not informative. We estimate that up to $0.2 \%$ of the non-Indigenous group may be misclassified Indigenous cases, indicating that up to $25 \%$ of Indigenous cases may be misclassified as non-Indigenous. If misclassified Indigenous cases had similar cancer survivals to other Indigenous cases, then the Indigenous survivals reported here are unbiased. If misclassified Indigenous cases had better survival than those correctly classified as Indigenous, perhaps because those incorrectly classified had better social, economic and environmental circumstances than those correctly classified as Indigenous, the Indigenous survivals reported here would be an underestimate to a small extent. Including misclassified Indigenous cases in the non-Indigenous group would have had an insignificant effect on nonIndigenous survival.

This study does not include people diagnosed with cancer after 2005, and follow-up of vital status after 2007, because national coded data on cause of death produced by the ABS has not been available to cancer registries since 2007 when data providers decided that the previous process to request and approve data access was no longer adequate. Efforts to develop a new approval process have been underway for several years but have not yet been successful [21]. Until cause of death data becomes available to cancer registers again, cause-specific cancer survival for Indigenous Australians cannot be updated for recent years.

One potentially large source of bias in this study is an information bias arising because Indigenous status in cancer registration data is partially derived from deaths data. The primary source of case ascertainment, pathology reports, does not include Indigenous status. Cancer registers rely on notifications from hospitals and death registrations as their main sources of Indigenous status data. If notifications from hospitals are significantly incomplete, people 
identified as Indigenous solely from death registrations will introduce differential misclassification of Indigenous status; Indigenous cases who have died will be more likely to be identified as Indigenous than Indigenous cases who have not died. The national cancer registration dataset does not include data on the source(s) of Indigenous status for each cancer registration, so the extent of this potential bias could not be assessed by this study; this requires specific investigation with cancer registries.

\section{Reasons for lower survival}

This study confirms, at the national level, previous reports from individual states/territories that cancer survival is lower for Indigenous than other Australians [4,22,23]. These studies have found that Indigenous people are more likely to have advanced disease when diagnosed, more likely to have chronic disease comorbidity, and less likely to be offered, choose, and complete curative treatment. However, these factors only partly explained the lower survival of Indigenous people suggesting that other unmeasured factors were also involved. These might include the less advantageous social, educational, economic, and environmental circumstances of many Indigenous Australians [1].

Excess mortality of Indigenous (compared with nonIndigenous) cancer cases was greatest in the first year after diagnosis; by the fifth year Indigenous cases had no excess mortality. This confirms at the national level a similar finding reported from Queensland [6]. This may reflect delayed cancer diagnosis (with more Indigenous cases having disseminated disease when diagnosed), lower access to curative cancer treatment, or higher levels of chronic disease comorbidity that complicate or preclude cancer treatment; all these factors have been reported as more common for Indigenous than other Australians $[2,23]$. The information bias arising from Indigenous cases being differentially identified from death certificates (described above) might also partly explain this finding, although cases diagnosed at the time of death were excluded from this analysis so it is not obvious how this bias would operate more in the first year after diagnosis than in later years. This needs to be further investigated.

Remoteness of residence was associated with lower survival. For Indigenous cases this disparity was very large; death rates were $65 \%$ higher for Indigenous people in very remote areas than in major cities. Thirty-one percent of Indigenous cases live in remote or very remote areas, compared to only $1 \%$ of non-Indigenous cases, so remoteness is a particularly serious detrimental factor for Indigenous people with cancer. Survival increased for Indigenous cases in remote areas, but in 2005 was still lower than for urban Indigenous cases, for whom survival had not improved at all. Survival improved considerably for non-Indigenous cancer cases, with a $28 \%$ decrease in death rate between 1991 and 2005. Improvements in cancer diagnosis, treatment and support services that have been successful in improving cancer outcomes for most Australians in recent years have apparently been less effective for Indigenous people. Access to, and acceptability of, diagnosis and treatment services are likely to be part of the explanation for the geographic disparity; the previous studies cited above provide little information about this. Further investigation of the reasons for the very poor survival of cancer cases from rural and remote areas, and how to overcome them, should be a high priority for both Indigenous and non-Indigenous people.

Population screening can lead to overdiagnosis of cancers that would not have otherwise been diagnosed before the person died from other causes. This may account for some of the improvement in survival for non-Indigenous Australians for breast and prostate cancers and to a lesser extent colorectal cancer over the period of this study, during which screening for these cancers became more common (screening for colorectal cancer increased more recently). Indigenous Australians have lower cancer screening participation, $[2,24]$ so they may be less susceptible to this overdiagnosis effect. There was little evidence of such an effect for breast and colorectal cancers in this study; the time trend in death rates was similar for Indigenous and non-Indigenous cases for both cancers (Table 6), but for prostate cancer the death rate decreased for non-Indigenous cases but not for Indigenous cases, which would be consistent with increasing overdiagnosis of prostate cancer among non-Indigenous cases only. For all cancers combined excluding these three screened cancers, the time trend for death rates (HR per year: non-Indigenous 0.97 , Indigenous 0.98 ) was similar to that when the screened cancers were included (nonIndigenous 0.98, Indigenous 0.99).

In recent years there has been increased attention to the disadvantage suffered by Indigenous people with cancer. In 2010 Cancer Australia (the Australian Government's cancer agency) commissioned a report on research priorities for Indigenous cancer control, [25] although it is still considering what action to take. A national roundtable on cancer control research for Indigenous Australians, convened in the same year by a senior Indigenous researcher, [26] led to the establishment of a national Centre of Research Excellence in Indigenous cancer control in 2012 [27]. The Centre has already established a National Indigenous Cancer Network of Indigenous cancer survivors and other community members, health professionals, and researchers [28]. Cancer services have started initiatives to improve cancer care in rural areas, such as the establishment of radiation oncology services in regional centres such as Darwin and Townsville [29] and use of telemedicine to provide access from remote communities to specialist oncologists [30]. Regular reporting 
of reliable Indigenous cancer survival statistics is essential to determine whether these initiatives are working.

\section{Conclusions}

Cancer survival is lower for Indigenous than other Australians, for all cancers combined, and many individual cancer sites. This disparity is greatest in remote areas and has increased over time because survival for Indigenous people has not improved as much as for Australians generally. Cancer survival statistics for the total Australian population do not necessarily apply to Indigenous Australians who develop cancer; more specific information is needed to assist them in making important treatment and personal decisions and to assess the effectiveness of efforts to reduce this disparity. Cancer registration data can be used to produce regular national survival statistics for Indigenous Australians, as they are for Australians generally. Despite data limitations, reliable statistics on cancer survival for Indigenous Australians can and should be reported on a regular basis by national and state/territory cancer statistics agencies.

\section{Additional files}

Additional file 1: Table S3a. Cause-specific compared with relative survival regression analysis, all cancers combined, Australia (excluding Victoria) 2001-2005 (full model). Description: Table S3, including hazard ratios for specific cancer sites.

Additional file 2: Table S7. Cause-specific compared with relative survival, five-year survival rate (\%) by Indigenous status and site, Australia excluding Victoria, 2001-2005.

Additional file 3: Table S4a. Regression analysis of cause-specific mortality for all cancers combined, Australia (excluding Victoria) 1991-2005 (full model). Description: Table 54 including hazard ratios for specific cancer sites.

Additional file 4: Table S5a. Time trends: regression analysis of causespecific mortality in two years after diagnosis for all cancers combined, Australia (excluding Victoria) 1991-2005 (full model). Description: Table S5 including hazard ratios for specific cancer sites.

Additional file 5: Table S8. Regression analysis for all cancers combined including an interaction term for year of diagnosis by remoteness category, hazard ratio ( $95 \%$ confidence interval), Australia (excluding Victoria) 1991-2005. Description: Separate regression analyses for Indigenous and non-Indigenous cases including interaction term to assess whether time trends vary by remoteness of residence.

\section{Abbreviations}

ABS: Australian bureau of statistics; ARIA: Accessibility/remoteness index of Australia; ICD-10: International classification of diseases, version 10; ICD-O-3: International classification of diseases for oncology, version 3.

\section{Competing interests}

The authors declare that they have no competing interest.

\section{Authors' contributions}

JCo, JCu, DR, MC, PJ, and TT conceived and initiated the study. JCo, JCu, XZ, and $P B$ refined the study design and undertook data management and/or analysis. KG assisted with data management and analysis. JCo, XZ, PB, and JCu helped draft the manuscript, with advice from DR, MC, PJ, KG, and TT. All authors read and approved the final manuscript.

\section{Acknowledgments}

This study was funded by NHMRC project grant number 436014. Joan Cunningham was supported by NHMRC Fellowship number 545200. The funding body was not involved in: study design; collection, analysis, or interpretation of data; writing the manuscript; or the decision to submit the manuscript for publication.

We thank state and territory Cancer Registries and the Australian Institute of Health and Welfare for access to cancer registrations data.

\section{Author details}

${ }^{1}$ Menzies School of Health Research, Charles Darwin University, Darwin, NT, Australia. ${ }^{2}$ Northern Territory Department of Health, Darwin, NT, Australia. ${ }^{3}$ Cancer Council Queensland, Brisbane, QLD, Australia. ${ }^{4}$ University of Sydney, Sydney, NSW, Australia. ${ }^{5}$ University of South Australia, Adelaide, SA, Australia. ${ }^{6}$ Murdoch Children's Research Institute, University of Melbourne, Melbourne, Vic, Australia. ${ }^{7}$ Australian Bureau of Statistics, Canberra, ACT, Australia. ${ }^{8}$ Department of Health Western Australia, Western Australian Cancer Registry, Perth, WA, Australia.

Received: 14 July 2013 Accepted: 15 January 2014

Published: 31 January 2014

\section{References}

1. Australian Institute of Health and Welfare, Australian Bureau of Statistics: The health and welfare of Australia's Aboriginal and Torres Strait Islander peoples. Canberra: ABS; 2008.

2. Cunningham J, Rumbold AR, Zhang X, Condon JR: Incidence, aetiology, and outcomes of cancer in Indigenous peoples in Australia. Lancet Oncol 2008, 9:585-595

3. Zhang $X$, Condon JR, Rumbold AR, Cunningham J, Roder DM: Estimating cancer incidence in indigenous Australians. Aust N Z J Public Health 2011 35:477-485.

4. South Australian Cancer Register: Cancer incidence, mortality and case survival in the South Australian Aboriginal population. In Epidemiology of cancer in South Australia, 1977 to 1996. Adelaide: South Australian Cancer Registry, South Australian Health Commission; 1997:11-19.

5. Condon JR, Armstrong BK, Barnes A, Zhao Y: Cancer incidence and survival for Indigenous Australians in the Northern Territory. Aust N Z J Public Health 2005, 29:123-128.

6. Cramb SM, Garvey G, Valery PC, Williamson JD, Baade PD: The first year counts: cancer survival among Indigenous and non-Indigenous Queenslanders, 1997-2006. Med J Aust 2012, 196:270-274.

7. Australian Institute of Health and Welfare, Cancer Australia, Australasian Association of Cancer Registries: Cancer survival and prevalence in Australia: cancers diagnosed from 1982 to 2004. Canberra: Australian Institute of Health and Welfare; 2008.

8. Australian Bureau of Statistics: Deaths Australia 2010. Canberra: ABS; 2011. vol Cat No 3302.0.

9. Sarfati $D$, Blakely $T$, Pearce $N$ : Measuring cancer survival in populations: relative survival vs cancer-specific survival. Int J Epidemio/ 2010, 39:598-610.

10. Australian Institute of Health and Welfare: Rural, regional and remote health, a guide to remoteness classifications. Canberra: Australian Institute of Health and Welfare; 2004

11. World Health Organisation: The international statistical classification of diseases and related health problems, tenth revision (2nd ed). Geneva: World Health Organisation; 2004.

12. Australian Bureau of Statistics: Experimental estimates and projections, Aboriginal and Torres Strait Islander Australians, Australia 1991-2021. Canberra: ABS; 2009. vol 3238.0.

13. International Classification of Diseases for Oncology, 3rd edition (ICD-0-3). [http://www.who.int/classifications/icd/adaptations/oncology/en/].

14. Life tables, Australia, 2008-2010. [http://www.abs.gov.au/AUSSTATS/abs@. nsf/Lookup/3302.0.55.001Main+Features12008-2010?OpenDocument].

15. Australian Bureau of Statistics: Experimental lifetables for Aboriginal and Torres Strait Islander Australians, 2005-2007. Canberra: ABS; 2009. vol 3302.0.55.003.

16. Ederer $\mathrm{F}$, Heise $\mathrm{H}$ : Instructions to IBM 650 Programmers in Processing Survival Computations. Methodological note No. 10. Bethesda: End Results Evaluation Section, National Cancer Institute; 1959.

17. Estimating and modelling relative survival. [http://www.pauldickman.com/ search_results.php?cx=partner-pub-9640800922108763\% 3At5ebmmxgx45\&cof=FORID\%3A10\&ie=ISO-8859- 
$1 \& q=$ ills\&sa=Search\&siteurl=www.pauldickman.com\%2Fpublications\% 2Findex.php\&ref=www.pauldickman.com\%2Findex.php\&ss=936j229056j5].

18. Stata Corporation: Stata. College Station, Texas: Stata Corp LP; 2009. 11.

19. Australian Bureau of Statistics: Deaths Australia (1998; 1999; 2001; 2005 editions). Canberra: ABS; 2012. Deaths Australia, vol 3302.0.

20. Australian Bureau of Statistics: Discussion paper: assessment of methods for developing life tables for Aboriginal and Torres Strait Islander Australians, 2006. Canberra: ABS; 2008. vol 3302.0.55.002.

21. Queensland Registry of Births Deaths and Marriages: Australian Coordinating Registry for Cause of Death Unit Record File: Cause of Death Unit Record File - final evaluation summary report for stakeholders. Brisbane; 2012.

22. Condon JR, Cunningham J, Barnes A, Armstrong B, Selva-Nayagam S: Cancer diagnosis and treatment in the Northern Territory - assessing health service performance for Indigenous Australians. Intern Med J 2006, 36:498-505.

23. Valery PC, Coory M, Stirling J, Green AC: Cancer diagnosis, treatment, and survival in Indigenous and non-Indigenous Australians: a matched cohort study. Lancet 2006, 367:1842-1848.

24. Roder D, Webster F, Zorbas H, Sinclair S: Breast screening and breast cancer survival in Aboriginal and Torres Strait Islander women of Australia. Asian PaC J Cancer Prev 2012, 13:147-155.

25. Miller J, Knott V, Wilson C, Cunningham J, Condon JR, Roder D, Bowden J, Chong A, Doherty T, Griffiths K, et al: Aboriginal and Torres Strait Islander Cancer Control Research Project. Canberra: Cancer Australia; 2010.

26. Garvey G, Cunningham J, Valery PC, Condon J, Roder D, Bailie R, Martin J, Olver I: Reducing the burden of cancer for Aboriginal and Torres Strait Islander Australians: time for a coordinated, collaborative, priority-driven, Indigenous-led research program. Med J Aust 2011, 194:530-531.

27. Lowitja Institute: $\$ 2.5 m$ cancer CRE sparked by Institute Roundtable. Wanka Pulka (7). Melbourne: Lowitja Institute; 2012.

28. National indigenous cancer network. [http://www.nican.org.au/].

29. Information about radiation oncology and radiotherapy services. [http://www.health.gov.au/internet/main/publishing.nsf/Content/health-roiradiother-index.htm].

30. Sabesan S, Larkins S, Evans R, Varma S, Andrews A, Beuttner P, Brennan S, Young M: Telemedicine for rural cancer care in North Queensland: bringing cancer care home. Aust J Rural Health 2013, 20:259-264.

doi:10.1186/1478-7954-12-1

Cite this article as: Condon et al:: Cancer survival for Aboriginal and Torres Strait Islander Australians: a national study of survival rates and excess mortality. Population Health Metrics 2014 12:1.

\section{Submit your next manuscript to BioMed Central and take full advantage of:}

- Convenient online submission

- Thorough peer review

- No space constraints or color figure charges

- Immediate publication on acceptance

- Inclusion in PubMed, CAS, Scopus and Google Scholar

- Research which is freely available for redistribution 